\title{
HIDROGEOQUÍMICA DE ÁGUAS MINERAIS ENVASADAS PARA O ESTADO DE SÃO PAULO
}

\author{
Isabella Longhi Bulia ${ }^{1} \&$ Jacinta Enzweiler ${ }^{2}$
}

RESUMO - A composição química das águas subterrâneas depende de processos hidrogeológicos, geoquímicos e biológicos, dos quais a interação água-rocha é o mais determinante. Águas minerais envasadas são essencialmente águas subterrâneas e, em princípio, constituem amostras destas. A análise físico-química e composicional de cinquenta e cinco amostras de águas minerais, representativas dos maiores sistemas aquíferos do Estado de São Paulo, permitiu identificar onze grupos, que espelham a heterogeneidade geológica do estado. Algumas amostras apresentaram composição exótica em relação ao seu grupo, possivelmente devido à influência antrópica.

\begin{abstract}
The chemical composition of groundwater depends on hydrogeological, geochemical and biological processes, among which the water-rock interaction plays a significant role. Bottled mineral waters produced by extraction of groundwater are, in principle, samples of the last. The physicochemical and compositional analysis of fifty-five different brands of bottled waters, representative of the primary aquifer systems of São Paulo state, allowed the identification of eleven groups of waters, which reflect the regional lithological diversity. The exotic composition of some samples compared to their group may be due to anthropogenic inputs.
\end{abstract}

Palavras-chave: Água mineral; Hidrogeoquímica; Água subterrânea.

\footnotetext{
${ }^{1}$ Pós-graduação em Geociências, Instituto de Geociências, UNICAMP, Rua João Pandiá Calógeras, 51, CEP 13083-870, Campinas (SP), e-mail: isabellalonghi@ige.unicamp.br;
${ }^{2}$ Departamento de Geologia e Recursos Naturais, Instituto de Geociências, UNICAMP, Rua João Pandiá Calógeras, 51, CEP 13083-870, Campinas (SP), tel. (19) 3521-4575, e-mail: jacinta@ige.unicamp.br.
} 


\section{INTRODUÇÃO}

A composição de águas naturais como as subterrâneas depende de processos hidrogeológicos, geoquímicos e biológicos, que por sua vez sofrem influência do clima, litologia, tempo de residência, distância do oceano, profundidade de circulação das águas dentro do aquífero, vegetação e relevo (Hem, 1985; Feitosa, 2000; Bertolo et al., 2007). Contribuições antrópicas oriundas de atividades agrícolas e descargas domésticas e industriais também podem ocorrer. Dos fatores naturais, a composição litológica do aquífero influencia preponderantemente a hidrogeoquímica das águas (Hem, 1985; Hounslow, 1995; Chapelle, 2003; Bertolo et al., 2007). As águas subterrâneas em contato com as rochas hospedeiras lixiviam os minerais presentes e estas reações são favorecidas em condições de baixas velocidades de circulação e de maiores pressão e temperatura (Feitosa, 2000). Como resultado, águas de composições químicas distintas podem ocorrer em escala local. Em outras palavras, de posse das concentrações dos principais íons presentes em águas subterrâneas é possível estabelecer uma série de relações iônicas que auxiliam na identificação de reações de dissolução/precipitação de minerais (dedução rocha-fonte) (Hounslow, 1995).

Águas minerais envasadas são essencialmente compostas de águas subterrâneas. Na prática, o que diferencia a água mineral da água subterrânea são seus usos, pois a origem é a mesma. Assim, o termo Água Mineral é utilizado para fins de engarrafamento e balneabilidade, e o termo Água Subterrânea quando seu uso é para a indústria, agricultura, abastecimento público, entre outros (CPRM, 2013).

A organização EuroGeoSurveys Geochemistry Expert Group realizou o projeto intitulado The European Bottled Water Geochemistry Project (Reimann e Birke, 2010), que consistiu na aquisição de 1785 "amostras" de águas envasadas provenientes de todo o continente europeu, nas quais foram determinados mais de 70 parâmetros. Apesar da amostragem inusitada, os dados de composição química das águas estudadas refletem satisfatoriamente os litotipos locais e regionalmente produzem um mapa geoquímico. O estudo também demonstrou que águas minerais envasadas podem ser uma alternativa barata e sem obstáculos logísticos e burocráticos para a amostragem de águas subterrâneas. No Brasil, Bertolo et al. (2007) utilizaram dados dos rótulos dos vasilhames das águas minerais envasadas em todo país e puderam associar as diferentes unidades aquíferas à geologia das fontes.

O estado de São Paulo responde por $22 \%$ da produção brasileira de águas minerais (CPRM, 2013). Esta produção é extraída de seis dos doze sistemas aquíferos reconhecidos no estado (Iritani e Ezaki, 2012). Desta forma, águas minerais representativas desses seis aquíferos foram amostradas 
e analisadas para validar a correspondência entre a sua composição e a da respectiva geologia dominante e caracterizar heterogeneidades dentro e entre as unidades aquíferas.

\section{GEOLOGIA REGIONAL}

A área de interesse abrange o estado de São Paulo, cujas unidades aquíferas (Figura 1) são condicionadas pela geologia do Escudo Sudeste e da Bacia do Paraná. Os sistemas aquíferos Litorâneo, Furnas, Diabásio e Cristalino Cárstico apresentam produtividade pequena e pouco representativa, em geral servindo apenas para o abastecimento local ou de pequenos centros, e por isso não serão considerados neste estudo (DAEE/IG/IPT/CPRM, 2005; Iritani e Ezaki, 2012). O sistema aquífero Taubaté também não será abordado, uma vez que não foram encontradas amostras para essa unidade. Abaixo seguem breves descrições dos sistemas aquíferos de interesse, baseadas em DAEE/IG/IPT/CPRM (2005) e Iritani e Ezaki (2012).

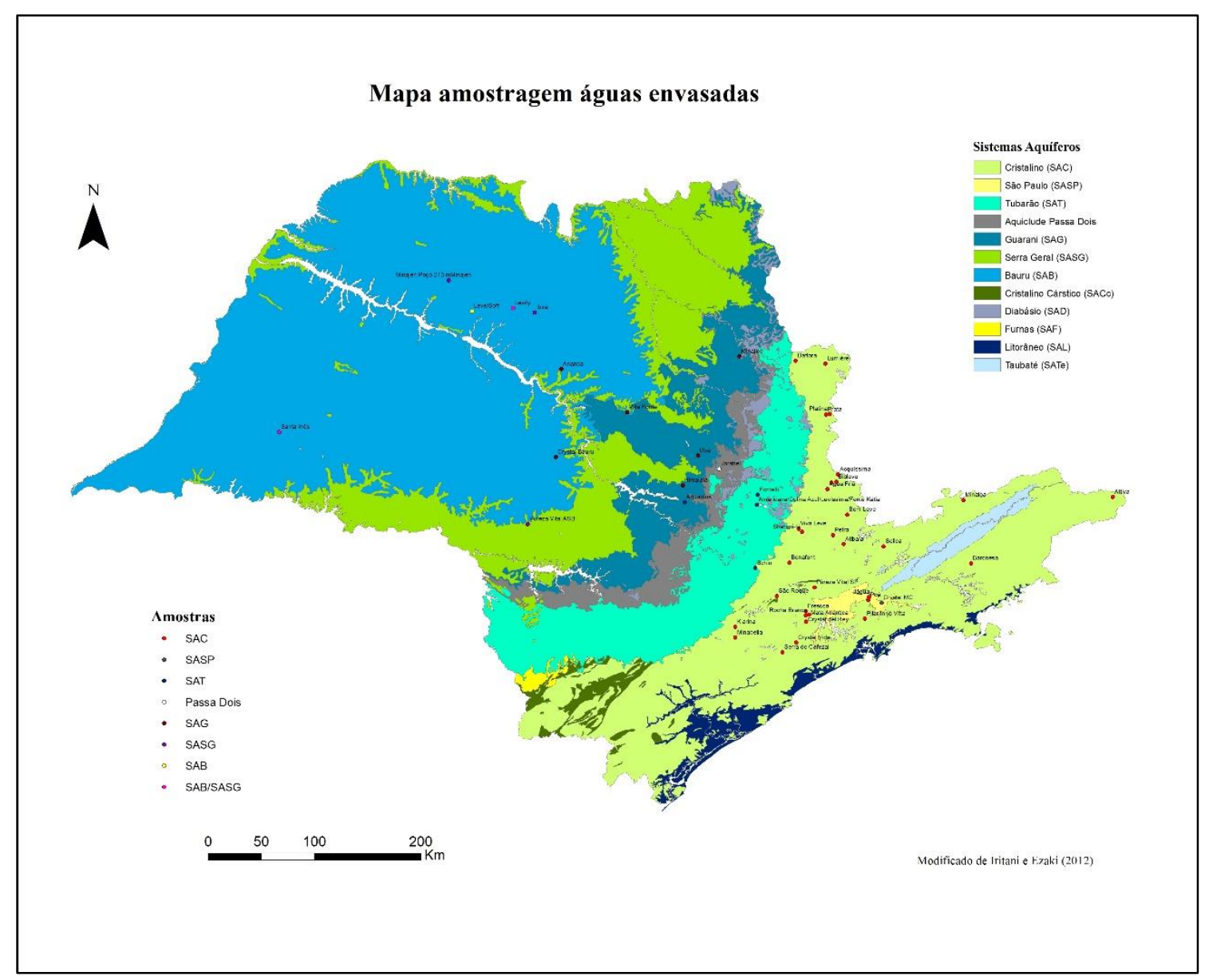

Figura 1. Mapa dos principais sistemas aquíferos do estado de São Paulo. O significado das siglas e breves descrições encontram-se no texto. Os pontos plotados se referem à localização das fontes ou poços das águas minerais amostradas. 
O sistema aquífero Cristalino (SAC), aflorante na porção leste do estado de São Paulo, é do tipo fraturado, de regime livre e constituído por rochas ígneas e metamórficas de idade précambriana e que compõem o embasamento cristalino, intercaladas localmente por rochas cristalinas mais jovens, mas de comportamento hidráulico semelhante. Suas rochas estendem-se para oeste do estado, mas nesses locais elas são recobertas pelas rochas sedimentares da Bacia do Paraná, sendo assim encontradas a maiores profundidades, o que inviabiliza sua exploração. Por se tratar de um sistema fraturado, sua produtividade é baixa em comparação às unidades sedimentares, No entanto, a sua localização em área densamente ocupada favorece a exploração e constitui uma alternativa para a obtenção de água potável. A qualidade da água é boa, mas a proximidade de grandes centros urbanos demanda atenção.

O sistema aquífero Serra Geral (SASG) também é do tipo fraturado e constituído pelos basaltos da formação de nome homônimo. Ocupa a metade oeste do estado e está, em sua maior parte, recoberto pelo sistema aquífero Bauru (SAB), mas apresenta comportamento livre na porção aflorante. A maioria dos poços explorados encontra-se na zona aflorante, que apresenta espessuras médias de $300 \mathrm{~m}$, mas estas aumentam na direção oeste, alcançando $1500 \mathrm{~m}$ no extremo oeste do estado. A sua produtividade é bastante variável, mas é mais expressiva que a do SAC, possivelmente devido à presença de vesículas, disjunções colunares, fraturas sub-horizontais e pequenas faixas de arenitos intercaladas aos derrames.

O sistema aquífero Tubarão (SAT) é do tipo sedimentar e em sua maior parte de comportamento livre, aflorando numa faixa que vai de nordeste a sul do estado, e apresenta espessura crescente de leste a oeste, chegando a 800 m no Grupo Itararé. Mais a oeste do estado, o aquífero mergulha em direção ao centro da bacia do Paraná e é confinado pelo aquiclude Passa Dois. É constituído pelos (i) Grupo Itararé e Formação Aquidauna, depositados em ambiente glacial continental com ingressões marinhas, e (ii) Grupo Guatá, depositado em ambiente marinho raso. O Grupo Itararé constitui sua principal unidade aquífera, com diamictitos, ritmitos, siltitos, argilitos, folhelhos, arenitos e conglomerados como litotipos presentes. Sua produtividade em geral é baixa, mas também há alguns valores mais expressivos (chamadas de "ilhas de elevada produtividade") em regiões de litologias mais arenosas e, com frequência, associadas a fraturas. Essa produtividade variável é característica da heterogeneidade geológica da unidade. A exploração se restringe às porções livres do aquífero, pois o rendimento nas suas regiões confinadas é relativamente mais baixo.

O sistema aquífero Guarani (SAG) é um sistema granular, localmente livre em sua porção aflorante, mas dominantemente confinado. É um dos maiores reservatórios mundiais de água doce conhecidos. Ocorre na região oeste do estado de São Paulo e se estende para os estados de Minas Gerais, Paraná, Mato Grosso e Mato Grosso do Sul e países vizinhos (Uruguai, Paraguai e XIX Congresso Brasileiro de Águas Subterrâneas 
Argentina). É composto por arenitos das Formações Pirambóia (ambiente flúvio-lacustre e eólico) e Botucatu (ambiente eólico), confinados pelos basaltos do SASG e pelas rochas do SAB. Sua porção livre não ultrapassa os $100 \mathrm{~m}$ de espessura, enquanto a porção confinada pode chegar a $400 \mathrm{~m}$. A uniformidade dos seus arenitos confere ao SAG características de um excelente reservatório, levando a sua utilização no abastecimento de várias cidades do oeste paulista.

O sistema aquífero Bauru (SAB) também é do tipo granular e apresenta comportamento livre por toda sua extensão. Localizado na porção oeste do estado, é formado pelas rochas sedimentares dos Grupos Bauru e Caiuá e não apresenta mais do que $300 \mathrm{~m}$ de espessura, o que torna atrativa a sua exploração. A sua deposição ocorreu sob duas fases principais de sedimentação, uma essencialmente desértica e outra de clima semi-árido, com maior presença de água, delimitando-o em duas unidades hidroestratigráficas principais: (i) porção superior, ou Bauru Superior, com arenitos intercalados por camadas de sedimentos finos, ou com arenitos que possuem uma cimentação carbonática e (ii) porção inferior, ou Bauru Inferior, onde predominam arenitos com baixo teor de material fino. Como resultado, a subunidade superior apresenta porosidade granular e contínua, mas não uniforme, o que imprime uma menor produtividade, e a subunidade inferior uma porosidade granular, contínua e de maior produtividade. A subunidade superior predomina em termos de área de ocorrência, situando-se nas áreas norte, leste e sudoeste do SAB, enquanto a subunidade inferior está localizada principalmente na zona oeste. O SAB possui um comportamento regionalmente livre, e ao mesmo tempo em que pode ser recarregado por toda a sua extensão é também mais vulnerável a contaminações antrópicas.

O sistema aquífero São Paulo (SASP) ocupa uma área irregular próxima a do município de São Paulo e arredores. É do tipo sedimentar com regime livre e se caracteriza pela intercalação de sedimentos arenosos e argilosos (sistema aquífero multicamadas), depositados sobre as rochas do embasamento cristalino. Suas rochas formadoras pertencem às unidades Grupo Taubaté, Formação Itaquaquecetuba e coberturas aluvionares e coluvionares, de sedimentação desenvolvida em ambientes de leque aluvial, sistemas fluviais entrelaçados e meandrantes e flúvio-lacustre. Caracterizado pela heterogeneidade litológica, as espessuras saturadas do SASP são variáveis, oscilando entre 100 e $250 \mathrm{~m}$. Consequentemente sua produtividade é média a baixa, sendo as regiões sul e leste do município de São Paulo em que se encontram os maiores valores de vazão. Possui comportamento livre, o que possibilita sua recarga por toda sua extensão, mas a sua localização, em área de intensa ocupação urbana e industrial, implica em elevada vulnerabilidade.

O Aquiclude Passa Dois é uma unidade de extensão regional que aflora em faixa estreita de norte a sul do estado, além de ser o marco divisório entre o SAT e o SAG. Formado em ambiente de deposição marinha, constitui assembleia litológica bastante homogênea composta predominantemente de folhelhos, siltitos, argilitos, calcários e dolomitos que ocorrem como XIX Congresso Brasileiro de Águas Subterrâneas 
camadas com diferentes espessuras, às vezes, ritmicamente intercaladas. Por ser constituído por sedimentos finos, sua produtividade é muito baixa, o que determina sua caracterização regional de aquiclude. Apesar disso, a presença de falhas locais proporciona um aumento pontual na produtividade, isto é, um aquitarde.

\section{MATERIAIS E MÉTODOS}

As águas minerais comercializadas no estado de São Paulo e analisadas pela CPRM desde 2012 serviram como banco de dados inicial, a partir do qual se compilou dados das fontes e poços, sistemas aquíferos prováveis e informações adicionais levantadas nos sítios eletrônicos das respectivas marcas. Um total de sessenta e quatro amostras, incluindo duplicatas, de água mineral foi selecionado para realizar o estudo. O número de amostras de cada unidade aquífera é proporcional ao número de fontes explotadas do respectivo aquífero (Figura 1 e Tabela 1). Critérios adicionais para a seleção foram a disponibilidade de informações geológicas da área da fonte e a facilidade de acesso.

Foram adquiridos volumes mínimos de 1,5 L (descartáveis e retornáveis) e no laboratório, alíquotas separadas para as análises foram mantidas sob refrigeração. Os parâmetros físicoquímicos ( $\mathrm{pH}$, condutividade elétrica, $\mathrm{CE}$, e total de sólidos dissolvidos, TDS) foram medidos com uma sonda multiparâmetros (Horiba U-52). A alcalinidade, expressa como bicarbonato ou este mais carbonato, foi determinada por titulação acidimétrica com o Titulador Automático G20 (Mettler Toledo) ou por titulação manual com $\mathrm{HCl}$ 0,01 mol/L, usando indicadores apropriados. Os ânions $\mathrm{F}^{-}, \mathrm{Cl}^{-}, \mathrm{NO}_{3}{ }^{-}, \mathrm{NO}_{2}^{-}, \mathrm{SO}_{4}{ }^{2-}$ e $\mathrm{PO}_{4}{ }^{3-}$ e os cátions $\mathrm{Li}^{+}, \mathrm{Na}^{+}, \mathrm{K}^{+}, \mathrm{Mg}^{2+}, \mathrm{Ca}^{2+}$ e $\mathrm{NH}_{4}^{+}$foram determinados por cromatografia de íons, CI (Dionex ICS 2500). Alíquotas de $35 \mathrm{~mL}$ foram acidificadas com $\mathrm{HNO}_{3} 1 \%$ para determinar as concentrações de $\mathrm{Si}$ e dos elementos-traço por espectrometria de massas com fonte de plasma indutivamente acoplado, ICP-MS (Thermo ${ }^{\circledR}$ XSeries II).

Para controle de qualidade, se inseriram duplicatas de amostras de forma sistemática. As duplicatas apresentaram reprodutibilidade de 0,1 a 7\%. Materiais de referência (certificados) foram analisados concomitantemente às amostras de estudo. $\mathrm{O}$ balanço iônico da maior parte das amostras foi inferior a 5\%. A comparação entre CE medida e a calculada foi verificada e apresentou diferença relativa menor que $20 \%$ para quase todas as amostras.

Os dados de íons principais foram comparados com os dos rótulos. Duas amostras apresentaram valores significativamente superiores aos do rótulo. De uma destas, nova amostra com data de envase distinta da primeira confirmou os resultados iniciais. 
A classificação dos tipos de águas foi efetuada segundo o diagrama de Piper. Os valores de principais íons dissolvidos serviram para obter relações de composição química das águas com a dos litotipos hospedeiros, conforme associações propostas por Bertolo et al. (2007). Cálculos de relações iônicas (Hounslow, 1995) foram utilizados para definir rochas-fonte e processos hidrogeoquímicos atuantes no aquífero.

Tabela 1. Amostras de águas minerais envasadas e respectivas localizações e sistemas aquíferos das fontes.

\begin{tabular}{|c|c|c|c|c|c|}
\hline Marca & Cidade & Unidade Aquífera & Marca & Cidade & Unidade Aquífera \\
\hline Prata & Águas da Prata & SAC (Alcalina) & $\begin{array}{l}\text { Pureza Vital } \\
\text { (SP) }\end{array}$ & São Paulo & SAC (Gnaisse) \\
\hline Platina & Águas da Prata & SAC (Alcalina) & Bonafont & Jundiaí & SAC (Gnaisse) \\
\hline Shangri-lá & Valinhos & SAC (Granito) & Frescca & Cotia & SAC (Gnaisse) \\
\hline Pilar & Ribeirão Pires & SAC (Granito) & Attiva & Bananal & SAC (Gnaisse) \\
\hline Inno Vitta & Ribeirão Pires & SAC (Granito) & Crystal (MC) & Mogi das Cruzes & SASP \\
\hline Lumière & Caconde & SAC (Granito) & Schin & Itu & SAT (Profunda) \\
\hline Rocha Branca & Embu das Artes & SAC (Granito) & Schin & Itu & SAT (Profunda) \\
\hline Klarina & Piedade & SAC (Granito) & Americana & Americana & SAT (Rasa) \\
\hline Minabella & Piedade & SAC (Granito) & Colina Azul & Americana & SAT (Profunda) \\
\hline Selica & $\begin{array}{l}\text { Piracaia } \\
\text { Bragança }\end{array}$ & SAC (Granito) & Levíssima & Americana & SAT (Profunda) \\
\hline Petra & Paulista & SAC (Granito) & Fonte Kátia & Americana & SAT (Profunda) \\
\hline Bem Leve & Pinhalzinho & SAC (Granito) & Fontelli & Limeira & SAT (Profunda) \\
\hline São Roque & São Roque & SAC (Granito) & Jorabel & Rio Claro & Passa Dois \\
\hline Viva Leve & Campinas & SAC (Granito) & Aquaplus & $\begin{array}{l}\text { Piracicaba } \\
\text { Boa Esperança }\end{array}$ & SAT \\
\hline Daflora & Mococa & SAC (Granito) & Villa Fonte & do Sul & SAG (Livre) \\
\hline Itágua & Itaquaquecetuba & SAC (Granito) & Ubá & Itirapina & SAG (Livre) \\
\hline Poá & Poá & SAC (Granito) & Himalaia & São Pedro & SAG (Livre) \\
\hline Água Fria & $\begin{array}{l}\text { Serra Negra } \\
\text { Campos do }\end{array}$ & SAC (Gnaisse) & $\begin{array}{l}\text { Minalice } \\
\text { Crystal }\end{array}$ & São Simão & SAG (Livre) \\
\hline Minalba & Jordão & SAC (Gnaisse) & (Bauru) & Bauru & SAG (Confinado) \\
\hline Lindoya Original & Lindóia & SAC (Gnaisse) & Ananda & Itápolis & SAG (Confinado) \\
\hline Bioleve & $\begin{array}{l}\text { Lindóia } \\
\text { Águas de }\end{array}$ & SAC (Gnaisse) & $\begin{array}{l}\text { Pureza Vital } \\
\text { (ASB) } \\
\text { Minajen }\end{array}$ & $\begin{array}{l}\text { Aguas de Santa } \\
\text { Bárbara }\end{array}$ & SASG (Típico) \\
\hline Acquíssima & Lindóia & SAC (Gnaisse) & (Poço 213 m) & Monte Aprazível & SASG (Profundo) \\
\hline Atibaia & Atibaia & SAC (Gnaisse) & Ibirá & $\begin{array}{l}\text { Ibirá } \\
\text { Presidente }\end{array}$ & SASG (Profundo) \\
\hline Baronesa & $\begin{array}{l}\text { Taubaté } \\
\text { Itapecerica da }\end{array}$ & SAC (Gnaisse) & Santa Inês & Prudente & SASG/SAB \\
\hline Crystal del Rey & $\begin{array}{l}\text { Serra } \\
\text { São Lourenço da }\end{array}$ & SAC (Gnaisse) & Levity & Potirendaba & SASG/SAB \\
\hline Crystal Vida & Serra & SAC (Gnaisse) & Soft & José Bonifácio & SAB \\
\hline Serra do Cafezal & Juquitiba & SAC (Gnaisse) & Minajen & Monte Aprazível & SAB \\
\hline Mata Atlântica & Embu das Artes & SAC (Gnaisse) & & & \\
\hline
\end{tabular}

\section{RESULTADOS E DISCUSSÃO}


A Tabela 2 apresenta os valores de parâmetros físico-químicos medidos, principais íons dissolvidos, sílica e elementos-traço selecionados para as amostras. A Tabela 3 contém os valores calculados para as relações iônicas de Hounslow (1995).

\subsection{Sistema Aquífero Cristalino (SAC)}

O SAC foi a unidade aquífera que apresentou maior número de exemplares amostrados. Tanto em comparação aos demais sistemas aquíferos como dentro da unidade, mostrou-se aquele mais heterogêneo também. Mesmo assim, foi possível fazer a distinção de dois grandes grupos, baseando-se nos principais litotipos locais das fontes: o grupo dos granitos e o grupo dos gnaisses.

Ambas podem ser classificadas como bicarbonatadas cálcico-sódicas (Figura 2B), porém as amostras de gnaisses exibiram um enriquecimento um pouco maior em magnésio, ao passo que as graníticas tendem para o polo do sódio. As amostras gnássicas apresentaram um $\mathrm{pH}$ em torno do neutro e valores de TDS mais elevados que as de granito, as quais são ligeiramente ácidas e de menores valores de TDS, comparativamente. Bertolo et al. (2007) subdividem o grupo dos gnaisses em gnaisses tipo I e II, no entanto esta distinção não foi observada no grupo de amostras estudado. Mas foi possível encontrar semelhanças entre as águas de gnaisses tipos I e II de Bertolo et al. (2007) com as de granitos e gnaisses, respectivamente, do presente estudo. As relações iônicas (Hounslow, 1995) indicam intemperismo de plagioclásio e de minerais máficos $\left(\mathrm{SiO}_{2} / \mathrm{Na}^{+}+\mathrm{K}^{+}-\mathrm{Cl}^{-}\right.$; $\left.\mathrm{Na}^{+}+\mathrm{K}^{+}-\mathrm{Cl}^{-} / \mathrm{Na}^{+}+\mathrm{K}^{+}-\mathrm{Cl}^{-}+\mathrm{Ca}^{2+} ; \mathrm{Na}^{+} / \mathrm{Na}^{+}+\mathrm{Cl}^{-} ; \mathrm{Ca}^{2+} / \mathrm{Ca}^{2+}+\mathrm{SO}_{4}{ }^{2-}\right)$, o que é condizente com a composição das rochas. O plagioclásio de granitos e gnaisses contribui com o $\mathrm{Ca}$ e $\mathrm{Na}$ dissolvidos, enquanto a biotita é fonte de magnésio.

Bertolo et al. (2007) também distinguem um grupo formado por águas provenientes das rochas alcalinas do maciço de Poços de Caldas, na cidade de Águas da Prata. No entanto, as duas amostras obtidas oriundas desse contexto não apresentaram as características descritas (bicarbonato, sódio e TDS altos) ou quantidades apreciáveis de sulfato e flúor. As amostras analisadas se mesclam entre as demais dos dois grupos no diagrama de Piper (Figura 2B). Szikszay e Teissedre (1977) identificaram dois tipos principais de fontes em Águas da Prata, as de rochas alcalinas, com $\mathrm{pH}$ neutro e alto teor de sólidos dissolvidos, e as de arenitos, com $\mathrm{pH}$ ácido e baixo teor de sólidos dissolvidos. As amostras do presente estudo se assemelham às do segundo grupo de Szikszay e Teissedre (1977), exceto pelo $\mathrm{pH}$.

Duas amostras (Itágua e Poá) classificadas no grupo dos granitos apresentaram concentrações de cloreto relativamente elevadas ( >10 mg/L). Teores mais elevados de sódio e nitrato nas mesmas águas sugerem contribuição de origem antrópica. Isto também é sugerido pela classificação das 


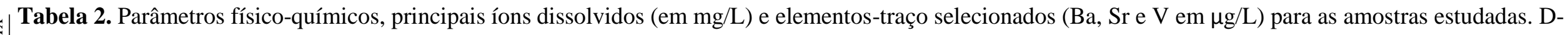
duplicata, T- triplicata, CE- condutividade elétrica $(\mu \mathrm{S} / \mathrm{cm})$ e TDS- total de sólidos dissolvidos (mg/L).

\begin{tabular}{|c|c|c|c|c|c|c|c|c|c|c|c|c|c|c|c|c|c|c|c|c|}
\hline & pH & $\mathbf{C E}$ & TDS & $\mathbf{F}^{-}$ & $\mathrm{Cl}^{-}$ & $\mathrm{SO}_{4}{ }^{2-}-\mathrm{S}$ & $\mathrm{Br}^{-}$ & $\mathrm{NO}_{3}{ }^{-}-\mathrm{N}$ & $\mathrm{PO}_{4}{ }^{3-}-\mathrm{P}$ & $\mathrm{HCO}_{3}{ }^{-}$ & $\mathrm{CO}_{3}{ }^{2-}$ & $\mathbf{L i}^{+}$ & $\mathbf{N a}^{+}$ & $\mathbf{K}^{+}$ & $\mathrm{Mg}^{2+}$ & $\mathrm{Ca}^{2+}$ & $\mathrm{SiO}_{2}$ & $\mathbf{B a}$ & $\mathbf{S r}$ & $\mathbf{V}$ \\
\hline Prata & 6,92 & 112 & 73 & 0,18 & 0,70 & 1,35 & $<\mathrm{LD}$ & 0,32 & 0,27 & 57,0 & - & $<\mathrm{LD}$ & 2,64 & 3,19 & 4,36 & 9,46 & 25,2 & 47,2 & 99,4 & 1,55 \\
\hline Platina & 7,42 & 84 & 54 & 0,10 & 0,55 & 0,13 & $<\mathrm{LD}$ & 0,11 & 0,06 & 49,3 & - & $<\mathrm{LD}$ & 11,8 & 2,55 & 0,3 & 4,27 & 45,2 & 6,15 & 276 & 2,63 \\
\hline Shangri-lá & 6,82 & 79 & 51 & 0,27 & 1,52 & 0,48 & $<\mathrm{LD}$ & 0,58 & 0,03 & 37,8 & - & 0,006 & 6,96 & 4,34 & 0,47 & 6,60 & 37,6 & 63,2 & 46,2 & 0,15 \\
\hline Pilar & 5,57 & 36 & 23 & 0,03 & 2,89 & 0,28 & $<\mathrm{LD}$ & 0,62 & $<\mathrm{LD}$ & 16,0 & - & $<\mathrm{LD}$ & 2,93 & 1,17 & 0,85 & 1,60 & 14,0 & 37,3 & 15,7 & 0,14 \\
\hline Inno Vitta & 5,47 & 38 & 25 & 0,03 & 2,93 & 0,42 & $<\mathrm{LD}$ & 0,69 & $<\mathrm{LD}$ & 15,3 & - & $<\mathrm{LD}$ & 3,08 & 1,24 & 0,99 & 1,69 & 13,4 & 40,5 & 16,9 & 0,12 \\
\hline Lumière & 6,44 & 131 & 85 & 0,11 & 1,48 & 0,18 & $<\mathrm{LD}$ & 0,44 & 0,05 & 92,7 & - & $<\mathrm{LD}$ & 6,50 & 3,39 & 5,61 & 10,7 & 55,4 & 67,25 & 72,96 & 1,77 \\
\hline Lumière (D) & 6,60 & 131 & 85 & 0,11 & 1,48 & 0,18 & $<\mathrm{LD}$ & 0,45 & 0,05 & 92,5 & - & $<\mathrm{LD}$ & 6,49 & 3,38 & 5,65 & 10,7 & 56,5 & 67,32 & 73,00 & 1,77 \\
\hline Rocha Branca & 6,81 & 143 & 93 & 0,75 & 2,18 & 3,00 & $<\mathrm{LD}$ & $<\mathrm{LD}$ & 0,08 & 88,7 & - & 0,012 & 14,39 & 3,10 & 2,26 & 15,16 & 60,8 & 3,74 & 81,8 & 0,35 \\
\hline Rocha Branca (D) & 6,98 & 146 & 95 & 0,75 & 2,19 & 3,01 & $<\mathrm{LD}$ & $<\mathrm{LD}$ & 0,08 & 89,0 & - & 0,012 & 14,45 & 3,12 & 2,26 & 15,15 & 61,7 & 3,79 & 82,6 & 0,34 \\
\hline Klarina & 6,30 & 34 & 22 & 0,05 & 1,96 & 0,02 & $<\mathrm{LD}$ & 1,39 & 0,03 & 9,0 & - & $<\mathrm{LD}$ & 3,11 & 1,65 & 0,88 & 1,23 & 13,7 & 63,7 & 31,4 & 0,19 \\
\hline Klarina (D) & 6,03 & 34 & 22 & 0,05 & 1,95 & 0,02 & $<\mathrm{LD}$ & 1,38 & 0,03 & 9,4 & - & $<\mathrm{LD}$ & 3,11 & 1,65 & 0,86 & 1,18 & 13,7 & 65,1 & 32,2 & 0,20 \\
\hline Minabella & 5,98 & 24 & 15 & 0,04 & 1,58 & 0,20 & $<\mathrm{LD}$ & 0,15 & $<\mathrm{LD}$ & 8,8 & - & $<\mathrm{LD}$ & 2,19 & 1,93 & 0,28 & 1,17 & 15,0 & 21,9 & 10,2 & 0,05 \\
\hline Selica & 7,14 & 104 & 68 & 0,44 & 0,67 & 0,79 & $<\mathrm{LD}$ & 0,08 & 0,04 & 60,8 & - & 0,005 & 9,83 & 2,31 & 2,00 & 10,8 & 39,2 & 16,9 & 118 & 0,33 \\
\hline Petra & 6,77 & 148 & 96 & 0,15 & 0,76 & 0,26 & $<\mathrm{LD}$ & 0,85 & 0,08 & 82,6 & - & 0,009 & 9,10 & 3,05 & 2,87 & 14,8 & 52,0 & 13,4 & 131 & 2,69 \\
\hline Bem Leve & 7,18 & 111 & 72 & 0,37 & 0,58 & 0,38 & $<\mathrm{LD}$ & 1,10 & 0,18 & 54,6 & - & 0,004 & 9,09 & 1,86 & 0,85 & 12,4 & 48,4 & 6,79 & 102 & 1,12 \\
\hline São Roque & 7,11 & 207 & 134 & 0,23 & 2,04 & 1,11 & $<\mathrm{LD}$ & 0,43 & 0,06 & 144 & - & 0,005 & 12,7 & 2,21 & 3,61 & 29,4 & 52,2 & 32,1 & 458 & 2,83 \\
\hline Viva Leve & 5,89 & 64 & 42 & 0,06 & 0,98 & 0,37 & $<\mathrm{LD}$ & 1,16 & $<\mathrm{LD}$ & 36,2 & - & $<\mathrm{LD}$ & 6,67 & 3,21 & 1,24 & 3,27 & 56,0 & 29,2 & 35,3 & 1,03 \\
\hline Daflora & 6,83 & 87 & 57 & 0,15 & 1,08 & 0,1 & $<\mathrm{LD}$ & 2,10 & 0,18 & 41,9 & - & $<\mathrm{LD}$ & 4,91 & 3,39 & 2,94 & 6,49 & 56,0 & 71,2 & 39,6 & 3,03 \\
\hline Itágua & 5,32 & 166 & 108 & 0,08 & 19,07 & 1,03 & 0,11 & 8,98 & 0,03 & 10,8 & - & 0,007 & 18,6 & 4,21 & 1,90 & 6,78 & 18,1 & 162 & 50,6 & 0,18 \\
\hline Poá & 5,86 & 104 & 68 & 0,04 & 10,40 & 0,79 & $<\mathrm{LD}$ & 5,54 & $<\mathrm{LD}$ & 14,4 & - & $<\mathrm{LD}$ & 10,1 & 2,78 & 1,92 & 4,88 & 11,8 & 95,6 & 34,2 & 0,27 \\
\hline Água Fria & 7,42 & 141 & 92 & 0,05 & 0,61 & 0,53 & $<\mathrm{LD}$ & 0,17 & 0,03 & 83,5 & - & 0,008 & 8,07 & 2,29 & 4,45 & 11,5 & 45,2 & 13,3 & 58,2 & 0,79 \\
\hline Minalba & 7,52 & 181 & 118 & 0,02 & 0,12 & 0,01 & $<\mathrm{LD}$ & 0,12 & $<\mathrm{LD}$ & 109 & - & $<\mathrm{LD}$ & 1,14 & 1,26 & 10,2 & 17,2 & 26,0 & 22,3 & 17,5 & 0,21 \\
\hline L. Original $27 / 5 / 15$ & 7,43 & 286 & 186 & 0,07 & 2,58 & 1,37 & $<\mathrm{LD}$ & 0,74 & 0,06 & 159 & - & 0,029 & 17,6 & 4,01 & 6,98 & 26,7 & 48,5 & 6,22 & 95,8 & 2,44 \\
\hline L. Original 5/9/15 & 6,81 & 233 & 151 & 0,10 & 1,98 & 1,12 & $<\mathrm{LD}$ & 0,67 & 0,04 & 115 & - & 0,024 & 15,3 & 3,88 & 5,63 & 24,3 & 45,5 & 10,6 & 96,6 & 2,13 \\
\hline Bioleve & 7,22 & 96 & 62 & 0,22 & 0,4 & 0,02 & $<\mathrm{LD}$ & 0,53 & 0,11 & 54,8 & - & $<\mathrm{LD}$ & 3,31 & 1,90 & 4,04 & 8,08 & 32,5 & 51,7 & 42,8 & 2,31 \\
\hline Acquíssima & 7,09 & 204 & 132 & 0,04 & 0,92 & 2,47 & $<\mathrm{LD}$ & $<\mathrm{LD}$ & 0,05 & 109 & - & 0,008 & 16,3 & 3,43 & 2,70 & 18,6 & 37,5 & 15,7 & 137 & 0,07 \\
\hline Atibaia & 7,01 & 99 & 64 & 0,09 & 0,5 & 0,17 & $<\mathrm{LD}$ & 0,51 & 0,05 & 71,58 & - & $<\mathrm{LD}$ & 2,93 & 2,2 & 3,84 & 11,0 & 46,3 & 15,35 & 71,4 & 6,53 \\
\hline Atibaia (D) & 7,03 & 100 & 65 & 0,09 & 0,5 & 0,17 & $<\mathrm{LD}$ & 0,52 & 0,04 & 71,65 & - & $<\mathrm{LD}$ & 2,91 & 2,2 & 3,81 & 11,0 & 45,3 & 15,27 & 71,1 & 6,34 \\
\hline Baronesa & 8,12 & 219 & 142 & 0,20 & 2,10 & 2,09 & $<\mathrm{LD}$ & 0,29 & 0,04 & 119,6 & - & 0,007 & 22,3 & 3,54 & 4,04 & 20,1 & 51,5 & 10,4 & 153 & 0,52 \\
\hline Baronesa (D) & 7,96 & 203 & 132 & 0,20 & 2,11 & 2,09 & $<\mathrm{LD}$ & 0,29 & 0,04 & 118,4 & - & 0,008 & 22,3 & 3,54 & 4,04 & 20,2 & 52,6 & 10,5 & 155 & 0,54 \\
\hline Baronesa (T) & 7,64 & 200 & 130 & 0,20 & 2,11 & 2,09 & $<\mathrm{LD}$ & 0,29 & 0,03 & 118,7 & - & 0,008 & 22,4 & 3,55 & 4,07 & 20,3 & 53,5 & 10,5 & 156 & 0,52 \\
\hline
\end{tabular}


Tabela 2. (Continuação).

\begin{tabular}{|c|c|c|c|c|c|c|c|c|c|c|c|c|c|c|c|c|c|c|c|c|}
\hline & pH & $\mathbf{C E}$ & TDS & $\mathbf{F}^{-}$ & $\mathrm{Cl}^{-}$ & $\mathrm{SO}_{4}{ }^{2-}-\mathrm{S}$ & $\mathrm{Br}^{-}$ & $\mathrm{NO}_{3}{ }^{-}-\mathrm{N}$ & $\mathrm{PO}_{4}{ }^{3-}-\mathrm{P}$ & $\mathrm{HCO}_{3}^{-}$ & $\mathrm{CO}_{3}{ }^{2-}$ & $\mathbf{L i}^{+}$ & $\mathrm{Na}^{+}$ & $\mathbf{K}^{+}$ & $\mathrm{Mg}^{2+}$ & $\mathrm{Ca}^{2+}$ & $\mathrm{SiO}_{2}$ & Ba & $\mathbf{S r}$ & $\mathbf{V}$ \\
\hline Crystal del Rey & 6,26 & 48 & 31 & 0,05 & 1,87 & 0,34 & $<\mathrm{LD}$ & 0,13 & 0,05 & 26,6 & - & 0,005 & 4,53 & 2,15 & 1,44 & 2,22 & 23,8 & 16,24 & 22,7 & 0,32 \\
\hline Crystal Vida & 6,93 & 110 & 71 & 0,26 & 2,11 & 2,22 & $<\mathrm{LD}$ & 0,03 & 0,06 & 66,4 & - & 0,013 & 12,07 & 3,01 & 1,95 & 8,47 & 59,2 & 1,74 & 75,7 & 0,19 \\
\hline S. do Cafezal & 7,03 & 118 & 77 & 0,22 & 2,45 & 3,40 & $<\mathrm{LD}$ & $<\mathrm{LD}$ & 0,02 & 67,5 & - & 0,009 & 11,48 & 3,02 & 2,49 & 10,43 & 47,9 & 5,25 & 87,7 & 0,04 \\
\hline S. do Cafezal (D) & 7,06 & 121 & 79 & 0,22 & 2,45 & 3,39 & $<\mathrm{LD}$ & $<\mathrm{LD}$ & 0,02 & 67,8 & - & 0,008 & 11,48 & 3,01 & 2,53 & 10,53 & 48,2 & 5,19 & 86,7 & 0,04 \\
\hline Mata Atlântica & 6,46 & 20 & 13 & 0,04 & 1,59 & 0,12 & $<\mathrm{LD}$ & 0,28 & 0,04 & 7,8 & - & $<\mathrm{LD}$ & 1,77 & 1,20 & 0,35 & 0,61 & 14,6 & 17,9 & 6,8 & 0,34 \\
\hline Pureza Vital (SP) & 7,12 & 317 & 206 & $<\mathrm{LD}$ & 8,35 & 0,35 & $<\mathrm{LD}$ & 0,71 & $<\mathrm{LD}$ & 168 & - & 0,006 & 2,79 & 3,77 & 16 & 30,5 & 44,6 & 49,4 & 20,9 & 3,39 \\
\hline Bonafont & 6,69 & 96 & 62 & 0,05 & 0,16 & 0,11 & $<\mathrm{LD}$ & 0,34 & 0,11 & 56,4 & - & $<\mathrm{LD}$ & 5,82 & 2,24 & 3,14 & 7,15 & 39,9 & 44,1 & 109 & 0,84 \\
\hline Frescca & 7,54 & 187 & 122 & 0,14 & 2,31 & 0,72 & $<\mathrm{LD}$ & 0,15 & 0,20 & 102 & - & 0,01 & 10,3 & 3,75 & 3,31 & 19,4 & 50,3 & 55,4 & 224 & 1,53 \\
\hline Attiva & 7,30 & 177 & 115 & 0,14 & 1,12 & 1,89 & $<\mathrm{LD}$ & $<\mathrm{LD}$ & 0,04 & 106 & - & $<\mathrm{LD}$ & 6,34 & 3,44 & 5,10 & 26,6 & 38,0 & 5,58 & 93,6 & 0,17 \\
\hline Crystal (MC) & 7,55 & 213 & 138 & 0,87 & 1,18 & 0,34 & $<\mathrm{LD}$ & 0,07 & 0,30 & 124 & - & $<\mathrm{LD}$ & 41,4 & 2,47 & 1,05 & 4,33 & 43,7 & 115 & 40,2 & 0,04 \\
\hline Schin (Sta Paula) & 7,30 & 321 & 209 & 0,03 & 16,0 & 3,07 & $<\mathrm{LD}$ & 2,94 & 0,15 & 134 & - & 0,009 & 23,5 & 2,15 & 10,4 & 22,8 & 36,7 & 124 & 271 & 0,83 \\
\hline $\operatorname{Schin}\left(\mathrm{N}^{\mathrm{a}} \operatorname{Sra} \mathrm{Ap}\right)$ & 7,40 & 401 & 260 & 0,08 & 13,6 & 4,22 & $<\mathrm{LD}$ & 3,98 & 0,12 & 164 & - & 0,010 & 25,9 & 2,05 & 12,8 & 36,1 & 42,0 & 253 & 698 & 1,51 \\
\hline Americana & 5,61 & 55 & 36 & $<\mathrm{LD}$ & 6,11 & 0,06 & 0,06 & 3,11 & $<\mathrm{LD}$ & 4,4 & - & $<\mathrm{LD}$ & 9,86 & 0,56 & $<\mathrm{LD}$ & $<\mathrm{LD}$ & 15,0 & 17,2 & 1,8 & 0,12 \\
\hline Colina Azul & 7,49 & 254 & 142 & 0,08 & 4,63 & 5,08 & $<\mathrm{LD}$ & 0,02 & $<\mathrm{LD}$ & 137 & - & 0,01 & 36,3 & 0,6 & 0,18 & 14,1 & 28,6 & 301 & 432 & 0,08 \\
\hline Levíssima & 7,60 & 311 & 202 & 0,41 & 18,9 & 16,4 & $<\mathrm{LD}$ & 0,02 & 0,02 & 98,0 & - & 0,012 & 48,4 & 0,83 & 0,19 & 18,9 & 31,6 & 63,0 & 380 & 0,56 \\
\hline Fonte Kátia & 6,89 & 324 & 210 & 0,34 & 20,7 & 17,6 & $<\mathrm{LD}$ & 0,04 & $<\mathrm{LD}$ & 106 & - & 0,013 & 50,2 & 0,76 & 0,26 & 19,5 & 33,5 & 138 & 565 & 0,28 \\
\hline Fontelli & 7,22 & 303 & 197 & 0,13 & 3,76 & 3,55 & $<\mathrm{LD}$ & 0,05 & 0,05 & 228 & - & 0,022 & 51,5 & 1,44 & 3,13 & 24,8 & 35,7 & 126 & 804 & 0,28 \\
\hline Jorabel & 6,54 & 11 & 7 & 0,01 & 0,93 & 0,01 & $<\mathrm{LD}$ & 0,43 & 0,02 & 3,4 & - & $<\mathrm{LD}$ & 0,94 & 0,94 & 0,10 & 0,52 & 9,94 & 10,0 & 3,0 & 0,06 \\
\hline Aquaplus & 5,45 & 46 & 30 & 0,03 & 2,81 & 0,22 & $<\mathrm{LD}$ & 3,34 & 0,02 & - & - & $<\mathrm{LD}$ & 0,67 & 2,14 & 2,38 & 1,00 & 14,0 & 253 & 28,3 & 0,09 \\
\hline Villa Fonte & 6,51 & 23 & 15 & 0,02 & 0,49 & 0,01 & $<\mathrm{LD}$ & 0,67 & 0,03 & 8,1 & - & $<\mathrm{LD}$ & 1,24 & 3,31 & 0,50 & 0,35 & 26,5 & 54,4 & 7,7 & 0,29 \\
\hline Ubá & 6,51 & 16 & 10 & 0,02 & 0,16 & $<\mathrm{LD}$ & $<\mathrm{LD}$ & 0,11 & 0,01 & 9,1 & - & $<\mathrm{LD}$ & 0,35 & 1,66 & 0,57 & 0,57 & 21,4 & 63,9 & 10,7 & 0,29 \\
\hline Himalaia & 5,98 & 19 & 12 & 0,02 & 0,27 & $<\mathrm{LD}$ & $<\mathrm{LD}$ & 0,38 & 0,02 & 10,4 & - & $<\mathrm{LD}$ & 0,98 & 2,49 & 0,45 & 0,72 & 24,7 & 68,7 & 12,8 & 0,45 \\
\hline Minalice & 7,73 & 116 & 76 & $<\mathrm{LD}$ & 0,05 & 0,05 & $<\mathrm{LD}$ & 0,04 & $<\mathrm{LD}$ & 71,4 & - & $<\mathrm{LD}$ & 19,3 & 0,98 & 0,95 & 5,28 & 19,2 & 15,4 & 139 & 8,69 \\
\hline Crystal (Bauru) & 7,89 & 131 & 85 & 0,06 & 0,09 & 0,04 & $<\mathrm{LD}$ & $<\mathrm{LD}$ & $<\mathrm{LD}$ & 76,4 & - & 0,005 & 20,3 & 1,89 & 0,34 & 8,59 & 20,3 & 1,07 & 383 & 0,92 \\
\hline Ananda & 9,70 & 400 & 260 & 1,23 & 2,77 & 4,20 & $<\mathrm{LD}$ & $<\mathrm{LD}$ & $<\mathrm{LD}$ & 35,1 & 90,9 & 0,005 & 95,7 & 0,29 & $<\mathrm{LD}$ & 0,94 & 57,8 & 3,47 & 8,54 & 0,29 \\
\hline Pureza Vital (ASB) & 7,40 & 146 & 95 & 0,06 & 0,20 & 0,02 & $<\mathrm{LD}$ & 0,01 & $<\mathrm{LD}$ & 81,8 & - & $<\mathrm{LD}$ & 10,0 & 2,80 & 0,10 & 19,38 & 41,8 & 8,91 & 78,1 & 3,66 \\
\hline Minajen (P. $213 \mathrm{~m}$ ) & 9,88 & 461 & 300 & 0,27 & 0,37 & 2,37 & $<\mathrm{LD}$ & $<\mathrm{LD}$ & $<\mathrm{LD}$ & 36,7 & 114 & $<\mathrm{LD}$ & 109 & 0,17 & $<\mathrm{LD}$ & 0,74 & 50,7 & 0,49 & 3,08 & 133 \\
\hline Ibirá & 9,59 & 511 & 332 & 0,31 & 3,42 & 14 & $<\mathrm{LD}$ & $<\mathrm{LD}$ & $<\mathrm{LD}$ & 30,6 & 82,6 & $<\mathrm{LD}$ & 99,5 & 0,34 & $<\mathrm{LD}$ & 0,96 & 43,2 & 0,34 & 23,7 & 67,5 \\
\hline Ibirá (Fonte 4) & 9,82 & 436 & 284 & 0,45 & 3,32 & 13,8 & $<\mathrm{LD}$ & $<\mathrm{LD}$ & $<\mathrm{LD}$ & 16,8 & 89,4 & $<\mathrm{LD}$ & 98,4 & 0,35 & $<\mathrm{LD}$ & 0,78 & 53,5 & 0,35 & 30,1 & 80,9 \\
\hline Santa Inês & 7,79 & 275 & 179 & 0,20 & 1,85 & 0,10 & $<\mathrm{LD}$ & 0,14 & 0,04 & 227 & - & 0,006 & 64,7 & 0,87 & 2,17 & 9,89 & 54,8 & 92,1 & 456 & 11,5 \\
\hline Levity & 8,58 & 159 & 103 & 0,14 & 0,30 & $<\mathrm{LD}$ & 0,41 & 0,06 & 0,02 & 55,2 & 13,9 & $<\mathrm{LD}$ & 26,4 & 1,02 & 1,05 & 6,50 & 26,2 & 30,5 & 276 & 96,1 \\
\hline Soft & 6,79 & 97 & 63 & 0,12 & 2,51 & $<\mathrm{LD}$ & $<\mathrm{LD}$ & 1,21 & 0,31 & 59,1 & - & $<\mathrm{LD}$ & 5,89 & 5,56 & 2,98 & 8,43 & 61,8 & 98,4 & 92,1 & 3,53 \\
\hline Minajen & 5,33 & 52 & 34 & 0,02 & 0,84 & $<\mathrm{LD}$ & $<\mathrm{LD}$ & 1,69 & $<\mathrm{LD}$ & 25,1 & - & $<\mathrm{LD}$ & 1,62 & 2,6 & 1,57 & 3,75 & 19,4 & 112 & 41,0 & 0,29 \\
\hline Limite de detecção & - & - & - & 0,001 & 0,015 & 0,010 & 0,005 & 0,003 & 0,015 & - & - & 0,004 & 0,02 & 0,05 & 0,03 & 0,05 & - & 0,009 & 0,009 & 0,003 \\
\hline
\end{tabular}




\begin{tabular}{|c|c|c|c|c|c|c|c|c|c|}
\hline & $\frac{\mathrm{HCO}_{3}^{-}}{\mathrm{CiO}}$ & $\mathrm{SiO}_{2}$ & $\mathrm{Na}^{+}+\mathrm{K}^{+}-\mathrm{Cl}^{-}$ & $\mathrm{Na}^{+}$ & $M g^{2+}$ & $\frac{\mathrm{Ca}^{2+}}{\cos ^{2-}}$ & $\frac{\mathrm{Ca}^{2+}+\mathrm{Mg} \mathrm{g}^{2+}}{\mathrm{cos}^{2-}}$ & $\frac{\mathrm{Cl}^{-}}{\Gamma \hat{n}}$ & $\mathrm{HCO}_{3}{ }^{-}$ \\
\hline & $\mathrm{SiO}_{2}$ & $\overline{\mathrm{Na}^{+}+\mathrm{K}^{+}-\mathrm{Cl}^{-}}$ & $\overline{\mathrm{Na}^{+}+\mathrm{K}^{+}-\mathrm{Cl}^{-}+\mathrm{Ca}^{2+}}$ & $\overline{\mathrm{Na}^{+}+\mathrm{Cl}^{-}}$ & $\mathrm{Mg}^{2+}+\mathrm{Ca}^{2+}$ & $\mathrm{Ca}^{2+}+\mathrm{SO}_{4}^{2-}$ & $\mathrm{SO}_{4}{ }^{2-}$ & ¿ânions & ¿ânions \\
\hline Prata & 2,23 & 2,38 & 0,27 & 0,85 & 0,43 & 0,85 & 9,87 & 0,02 & 0,87 \\
\hline Platina & 1,08 & 1,34 & 0,73 & 0,97 & 0,10 & 0,96 & 29 & 0,02 & 0,95 \\
\hline Shangri-lá & 0,99 & 1,69 & 0,53 & 0,88 & 0,11 & 0,92 & 12 & 0,06 & 0,83 \\
\hline Pilar & 1,13 & 3,07 & 0,49 & 0,61 & 0,47 & 0,82 & 8,58 & 0,20 & 0,64 \\
\hline Inno Vitta & 1,12 & 2,70 & 0,50 & 0,62 & 0,49 & 0,76 & 6 & 0,20 & 0,61 \\
\hline Lumière & 1,65 & 2,81 & 0,38 & 0,87 & 0,46 & 0,98 & 89 & 0,03 & 0,94 \\
\hline Lumière (D) & 1,61 & 2,88 & 0,38 & 0,87 & 0,47 & 0,98 & 89 & 0,03 & 0,94 \\
\hline Rocha Branca & 1,44 & 1,57 & 0,46 & 0,91 & 0,20 & 0,80 & 5,03 & 0,04 & 0,83 \\
\hline Rocha Branca (D) & 1,42 & 1,59 & 0,46 & 0,91 & 0,20 & 0,80 & 5,02 & 0,04 & 0,83 \\
\hline Klarina & 0,65 & 1,86 & 0,67 & 0,71 & 0,54 & 0,98 & 93 & 0,18 & 0,48 \\
\hline Klarina (D) & 0,68 & 1,87 & 0,67 & 0,71 & 0,54 & 0,97 & 84 & 0,18 & 0,49 \\
\hline Minabella & 0,58 & 2,50 & 0,63 & 0,68 & 0,28 & 0,82 & 6,43 & 0,21 & 0,67 \\
\hline Selica & 1,53 & 1,39 & 0,47 & 0,96 & 0,23 & 0,92 & 14 & 0,02 & 0,91 \\
\hline Petra & 2,86 & 0,81 & 0,45 & 0,96 & 0,19 & 0,86 & 7,47 & 0,01 & 0,91 \\
\hline Bem Leve & 1,11 & 1,89 & 0,41 & 0,96 & 0,10 & 0,96 & 30 & 0,02 & 0,86 \\
\hline São Roque & 2,72 & 1,58 & 0,27 & 0,91 & 0,17 & 0,95 & 25 & 0,02 & 0,93 \\
\hline Viva Leve & 0,64 & 2,71 & 0,68 & 0,91 & 0,38 & 0,88 & 11 & 0,04 & 0,81 \\
\hline Daflora & 0,74 & 3,45 & 0,45 & 0,88 & 0,43 & 0,98 & 91 & 0,03 & 0,77 \\
\hline Itágua & 0,59 & 0,79 & 0,53 & 0,60 & 0,32 & 0,84 & 7,67 & 0,38 & 0,12 \\
\hline Poá & 1,20 & 0,91 & 0,47 & 0,60 & 0,39 & 0,83 & 8,15 & 0,30 & 0,24 \\
\hline Água Fria & 1,82 & 1,92 & 0,41 & 0,95 & 0,39 & 0,95 & 28 & 0,01 & 0,95 \\
\hline Minalba & 4,16 & 5,53 & 0,08 & 0,94 & 0,49 & 1,00 & 2721 & 0,00 & 0,99 \\
\hline L.Original 27/5/15 & 3,23 & 1,01 & 0,37 & 0,91 & 0,30 & 0,94 & 22 & 0,03 & 0,92 \\
\hline L.Original 5/9/15 & 2,49 & 1,07 & 0,37 & 0,92 & 0,28 & 0,95 & 24 & 0,03 & 0,91 \\
\hline Bioleve & 1,66 & 2,98 & 0,31 & 0,93 & 0,45 & 1,00 & 786 & 0,01 & 0,93 \\
\hline Acquíssima & 2,86 & 0,81 & 0,45 & 0,96 & 0,19 & 0,86 & 7,47 & 0,01 & 0,91 \\
\hline Atibaia & 1,52 & 4,54 & 0,24 & 0,90 & 0,37 & 0,98 & 82 & 0,01 & 0,95 \\
\hline Atibaia (D) & 1,54 & 4,52 & 0,24 & 0,90 & 0,36 & 0,98 & 81 & 0,01 & 0,95 \\
\hline Baronesa & 2,29 & 0,86 & 0,50 & 0,94 & 0,25 & 0,89 & 10 & 0,03 & 0,90 \\
\hline Baronesa (D) & 2,21 & 0,88 & 0,50 & 0,94 & 0,25 & 0,89 & 10 & 0,03 & 0,90 \\
\hline Baronesa $(\mathrm{T})$ & 2,19 & 0,89 & 0,50 & 0,94 & 0,25 & 0,89 & 10 & 0,03 & 0,90 \\
\hline Crystal del Rey & 1,10 & 1,99 & 0,64 & 0,79 & 0,52 & 0,84 & 11 & 0,10 & 0,83 \\
\hline
\end{tabular}


Tabela 3. (Continuação).

\begin{tabular}{|c|c|c|c|c|c|c|c|c|c|}
\hline & $\frac{\mathrm{HCO}_{3}{ }^{-}}{\mathrm{SiO}_{2}}$ & $\frac{\mathrm{SiO}_{2}}{\mathrm{Na}^{+}+\mathrm{K}^{+}-\mathrm{Cl}^{-}}$ & $\frac{\mathrm{Na}^{+}+\mathrm{K}^{+}-\mathrm{Cl}^{-}}{\mathrm{Na}^{+}+\mathrm{K}^{+}-\mathrm{Cl}^{-}+\mathrm{Ca}^{2+}}$ & $\frac{\mathrm{Na}^{+}}{\mathrm{Na}^{+}+\mathrm{Cl}^{-}}$ & $\frac{M g^{2+}}{M g^{2+}+C a^{2+}}$ & $\frac{\mathrm{Ca}^{2+}}{\mathrm{Ca}^{2+}+\mathrm{SO}_{4}^{2-}}$ & $\frac{\mathrm{Ca}^{2+}+\mathrm{Mg}^{2+}}{\mathrm{SO}_{4}{ }^{2-}}$ & $\frac{C l^{-}}{\sum \text { ânions }}$ & $\frac{\mathrm{HCO}_{3}{ }^{-}}{\sum \text { ânions }}$ \\
\hline Crystal Vida & 1,10 & 1,82 & 0,56 & 0,90 & 0,27 & 0,75 & 4,21 & 0,05 & 0,83 \\
\hline S.do Cafezal & 1,39 & 1,57 & 0,49 & 0,88 & 0,28 & 0,71 & 3,43 & 0,05 & 0,79 \\
\hline S.do Cafezal (D) & 1,38 & 1,58 & 0,49 & 0,88 & 0,28 & 0,71 & 3,47 & 0,05 & 0,79 \\
\hline Mata Atlântica & 0,52 & 3,88 & 0,67 & 0,63 & 0,48 & 0,81 & 8,22 & 0,22 & 0,63 \\
\hline P. Vital (SP) & 3,71 & $-41,82$ & $-0,01$ & 0,34 & 0,46 & 0,99 & 130 & 0,08 & 0,90 \\
\hline Bonafont & 1,39 & 2,17 & 0,46 & 0,98 & 0,42 & 0,98 & 90 & 0,00 & 0,96 \\
\hline Frescca & 2,00 & 1,75 & 0,33 & 0,87 & 0,22 & 0,96 & 28 & 0,04 & 0,93 \\
\hline Attiva & 2,76 & 1,90 & 0,20 & 0,90 & 0,24 & 0,92 & 15 & 0,02 & 0,92 \\
\hline Crystal (MC) & 2,80 & 0,40 & 0,89 & 0,98 & 0,29 & 0,91 & 14 & 0,02 & 0,95 \\
\hline Schin (Sta Paula) & 3,59 & 0,98 & 0,35 & 0,69 & 0,43 & 0,86 & 10 & 0,15 & 0,72 \\
\hline $\operatorname{Schin}\left(N^{a} \operatorname{Sra} A p\right)$ & 3,86 & 0,88 & 0,31 & 0,75 & 0,37 & 0,87 & 11 & 0,11 & 0,74 \\
\hline Americana & 0,29 & 0,92 & 1,00 & 0,71 & - & 0,00 & 0,00 & - & - \\
\hline Colina Azul & 4,71 & 0,33 & 0,68 & 0,92 & 0,02 & 0,69 & 2,27 & 0,05 & 0,83 \\
\hline Levíssima & 3,04 & 0,33 & 0,63 & 0,80 & 0,02 & 0,48 & 0,94 & 0,17 & 0,50 \\
\hline Fonte Kátia & 3,12 & 0,34 & 0,62 & 0,79 & 0,02 & 0,47 & 0,91 & 0,17 & 0,51 \\
\hline Fontelli & 6,29 & 0,27 & 0,64 & 0,95 & 0,17 & 0,85 & 6,75 & 0,03 & 0,92 \\
\hline Jorabel & 0,34 & 4,30 & 0,60 & 0,61 & 0,25 & 0,97 & 39 & 0,23 & 0,48 \\
\hline Aquaplus & 0,00 & 48,44 & 0,09 & 0,27 & 0,80 & 0,79 & 18 & 0,24 & 0,00 \\
\hline Villa Fonte & 0,30 & 3,54 & 0,88 & 0,80 & 0,70 & 0,96 & 84 & 0,07 & 0,67 \\
\hline Ubá & 0,42 & 6,68 & 0,65 & 0,78 & 0,62 & 1,00 & - & 0,03 & 0,92 \\
\hline Himalaia & 0,41 & 4,16 & 0,73 & 0,85 & 0,51 & 1,00 & - & 0,04 & 0,82 \\
\hline Minalice & 3,66 & 0,37 & 0,77 & 1,00 & 0,23 & 0,99 & 110 & 0,00 & 0,99 \\
\hline Crystal (Bauru) & 3,71 & 0,36 & 0,68 & 1,00 & 0,06 & 0,99 & 179 & 0,00 & 0,99 \\
\hline Ananda & 0,60 & 0,24 & 0,99 & 0,98 & 0,00 & 0,15 & 0,18 & 0,03 & 0,23 \\
\hline P.Vital (ASB) & 1,93 & 1,38 & 0,34 & 0,99 & 0,01 & 1,00 & 977 & 0,00 & 0,99 \\
\hline Minajen (P. 213m) & 0,71 & 0,18 & 0,99 & 1,00 & 0,00 & 0,20 & 0,25 & 0,00 & 0,22 \\
\hline Ibirá & 0,70 & 0,17 & 0,99 & 0,98 & 0,00 & 0,05 & 0,05 & 0,02 & 0,12 \\
\hline Ibirá (Fonte 4) & 0,31 & 0,21 & 0,99 & 0,98 & 0,00 & 0,04 & 0,04 & 0,03 & 0,10 \\
\hline Santa Inês & 4,08 & 0,33 & 0,85 & 0,98 & 0,27 & 0,99 & 103 & 0,01 & 0,98 \\
\hline Levity & 2,08 & 0,37 & 0,78 & 0,99 & 0,21 & 1,00 & - & 0,01 & 0,65 \\
\hline Soft & 0,94 & 3,14 & 0,44 & 0,78 & 0,37 & 1,00 & - & 0,06 & 0,85 \\
\hline Minajen & 1,27 & 2,85 & 0,38 & 0,75 & 0,41 & 1,00 & - & 0,04 & 0,74 \\
\hline
\end{tabular}


águas como bicarbonatadas cloretadas e pelas relações iônicas que indicam troca catiônica, intemperismo de feldspatos e presença de água salobra, o que não é coerente.

A amostra de Campos do Jordão, Água Santa (Minalba), apresentou características iônicas do grupo dos gnaisses, diferente do encontrado por Szikszak e Teissedre (1979) que indicaram influência de dolomito para a água da mesma fonte. Bertolo et al. (2007) também mencionam, para a mesma área, águas semelhantes às em contato com mármores dolomíticos do grupo Açungui no Paraná, com predomínio de intemperismo de carbonatos e precipitação de calcita e dolomita. No entanto, esses resultados não se confirmaram nesse estudo.

\subsection{Sistema Aquífero São Paulo (SASP)}

A amostra estudada é bicarbonatada sódica, possui $\mathrm{pH}$ neutro e as relações iônicas indicam troca catiônica como fonte de sódio $\left(\mathrm{SiO}_{2} / \mathrm{Na}^{+}+\mathrm{K}^{+}-\mathrm{Cl}^{-} ; \mathrm{Na}^{+} / \mathrm{Na}^{+}+\mathrm{Cl}^{-}\right)$. Estes dados se assemelham aos descritos por Bertolo (2007). Parisot e Rebouças (1983) estudaram 47 amostras de águas subterrâneas do município de São Paulo e as dividiram em dois tipos, as pertencentes ao aquífero sedimentar e as ao aquífero cristalino, sendo as do cristalino mais mineralizadas, enquanto as do sedimentar pouco mineralizadas. Nesse estudo, a amostra do SASP (Crystal MC) apresentou valor TDS superior aos verificados por Parisot e Rebouças (1983) (3-50 mg/L), mas a classificação pelo diagrama de Piper foram correspondentes.

\subsection{Sistema Aquífero Tubarão (SAT)}

As amostras estudadas são bicarbonatadas cálcico-sódicas (Figura 2A), de pH aproximadamente neutro e TDS mais alto, características esperadas para o SAT (Iritani e Ezaki, 2012). As amostras de Itu (Schin), são marcadas por um enriquecimento em magnésio. Este é atribuído a proximidade do SAC. Também em Itu, Iritani et al. (2011) encontraram poços influenciados por rochas sedimentares, com características bicarbonatadas sódicas a cálcicas, poços influenciados por rochas cristalinas, com características bicarbonatadas cálcicas, e poços mistos, mas que apresentavam predomínio das características sedimentares.

As amostras de Americana (Americana, Colina Azul, Levíssima e Fonte Kátia) são bicarbonatas cálcico-sódicas e cloretadas sódicas, sendo as últimas mais ácidas. Elas correspondem a dois tipos de águas descritos por Montanheiro et al. (2014). Os resultados podem ser interpretados como de amostras sotopostas na coluna de água, isto é, a cloretada sódica e mais diluída (Americana) oriunda de uma nascente, a seguir a água bicarbonatada cálcico-sódica com mais sólidos dissolvidos (Colina Azul) proveniente de $100 \mathrm{~m}$ de profundidade, e por fim as de $200 \mathrm{~m}$ de 
profundidade (Levíssima e Fonte Kátia) águas cálcico-sódicas mais salinas e com maiores teores de sulfato. A heterogeneidade composicional das águas do SAT foi atribuída por Vidal (2002) à descontinuidade de suas litofácies.

Pelas relações iônicas, a fonte de sódio poderia ser troca iônica ou dissolução de albita $\left(\mathrm{SiO}_{2} / \mathrm{Na}^{+}+\mathrm{K}^{+}-\mathrm{Cl}^{-} ; \mathrm{Na}^{+} / \mathrm{Na}^{+}+\mathrm{Cl}^{-}\right)$. Vidal (2002) encontrou em lâmina evidências de dissolução de feldspatos (albita) e presença de argilas, que poderiam realizar a troca do sódio (caulinitas e illitaesmectitas) substituindo silicatos ou como minerais autigênicos. A presença de feldspatos também pode explicar a fonte de cálcio indicada como intemperismo de silicatos pelas razões iônicas $\left(\mathrm{Na}^{+}+\mathrm{K}^{+}-\mathrm{Cl}^{-} / \mathrm{Na}^{+}+\mathrm{K}^{+}-\mathrm{Cl}^{-}+\mathrm{Ca}^{2+} ; \mathrm{Ca}^{2+} / \mathrm{Ca}^{2+}+\mathrm{SO}_{4}{ }^{2-}\right)$. As relações iônicas ainda apontam para possível dissolução de gipsita ( $\mathrm{HCO}_{3}{ }^{-} /$¿ânions). Bocardi et al. (2008) identificaram cimento composto por anidrita, formado durante a compactação química do Grupo Itararé.

Por fim, duas amostras (Jorabel e Aquaplus), que são inseridas em contexto diferente daquele do SAT pelo DNPM (2015), foram classificadas nesse por semelhanças entre essas e exemplares da unidade, o que será discutido a seguir.

A água da marca Jorabel foi classificada como cloretada sódica e possivelmente é de circulação rasa. Ela é descrita como pertencente ao Aquiclude Passa Dois, porém esse sistema, denominado Corumbataí por Bertolo et al. (2007), apresenta águas fortemente bicarbonatadas cálcicas por estarem presente em formações de origem carbonática (Formação Irati). Oliva e Kiang (2002) estudaram as águas subterrâneas de Rio Claro e encontraram três unidades passíveis de exploração: Rio Claro, Irati-Corumbataí e Subgrupo Itararé. As águas da Formação Rio Claro (mesma unidade classificada pela DNPM, 2015 para a Jorabel) são do tipo bicarbonatadas cálcicosódicas, mas também identificaram duas amostras com cloreto mais elevado, atribuído à contaminação de origem antrópica.

Segundo o DNPM (2015), a fonte da água Aquaplus foi classificada como pertencente a porção livre do SAG (Figura 1), todavia suas características são muito diferentes das esperadas para o grupo, conforme serão introduzidas no próximo subitem, elas são sulfatadas-cloretadas-sódicas. Tais características já foram descritas no sistema, mas para porções confinadas (Campos, 2013). Além disso, a amostra apresentava valores significativos de nitrato, o que indica influência de origem antrópica.

\subsection{Sistema Aquífero Guarani (SAG)}

As amostras provenientes do SAG exibiram baixas concentrações de sais dissolvidos, pH ligeiramente ácido e foram classificadas como bicarbonatadas sódico-magnesianas (Figura 2C). Tendem a apresentar composição homogênea, mas uma das amostras (Minalice) apresentou 
concentrações iônicas mais elevadas e pH próximo a 7. O SAG é apresenta porções livre e confinada. Bertolo et al. (2007) apresentam dados da primeira, com um grupo bem homogêneo, de $\mathrm{pH}$ ligeiramente ácido, bicarbonatadas cálcicas e baixo TDS.

As razões iônicas indicaram intemperismo de minerais ferromagnesianos e plagioclásio $\left(\mathrm{SiO}_{2} / \mathrm{Na}^{+}+\mathrm{K}^{+}-\mathrm{Cl}^{-} ; \mathrm{Na}^{+}+\mathrm{K}^{+}-\mathrm{Cl}^{-} / \mathrm{Na}^{+}+\mathrm{K}^{+}-\mathrm{Cl}^{-}+\mathrm{Ca}^{2+}\right)$ para três das amostras inseridas na porção livre do SAG. Wu e Caetano-Chang (1992) identificaram alteração de feldspatos para os arenitos Pirambóia e Botucatu na região centro-leste do estado de São Paulo.

Apesar da homogeneidade das amostras do SAG mencionadas, dada a extensão regional do aquífero, o SAG passa por modificações desde a área de recarga até a região mais confinada no extremo oeste do estado (Bertolo et al., 2007; Campos, 2013). Há uma evolução natural da circulação regional das águas no sentido de enriquecimento em $\mathrm{HCO}_{3}{ }^{-}<\mathrm{SO}_{4}{ }^{2-}<\mathrm{Cl}^{-}$e $\mathrm{Ca}^{2+}<\mathrm{Mg}^{2+}<\mathrm{Na}^{+}$, o que permite com que uma água possa vir a ter características muito distintas daquelas da rocha em que circulam (Campos, 1987). Em sua zona de recarga, as águas do SAG geralmente apresentam temperaturas compreendidas entre 22 e $27^{\circ} \mathrm{C}$, $\mathrm{pH}$ entre 5,4 e 9,2 e salinidade inferior a $50 \mathrm{mg} / \mathrm{L}$, sendo o tipo químico predominante as águas bicarbonatadas cálcicas ou bicarbonatadas cálcico-magnesianas. Conforme se avança para as áreas confinadas as temperaturas variam entre 22 e $58,7^{\circ} \mathrm{C}$, o pH entre 6,3 e 9,8 e a salinidade entre 50 e $500 \mathrm{mg} / \mathrm{L}$, sendo os tipos químicos predominantes as águas bicarbonatadas cálcicas e bicarbonatadas sódica seguidas da sulfatadas-cloretadas sódicas (Campos, 2013).

Duas amostras (Crystal Bauru e Ananda) foram classificadas como oriundas das áreas confinadas do SAG. Elas apresentaram maiores teores de sólidos dissolvidos e valores de $\mathrm{pH}$ mais elevados. A Crystal (Bauru), que apesar de localizada em zonas de exploração do SAB, é extraída a mais de $300 \mathrm{~m}$ de profundidade, alcançando os níveis do SAG (DNPM, 2015). Ela exibe características muito semelhantes à água Minalice, que, por sua vez, está inserida na porção livre, o que poderia indicar um trend de pouca evolução da composição nesse ponto. A amostra Ananda, apresentou valores significativos de sódio e $\mathrm{pH}>9$, o que é previsto com um maior grau de confinamento. Apesar disto, essas características permitem classificar tais amostras como do SAB, (ver subitem 4.6).

As relações iônicas das amostras indicam semelhança entre Minalice e Crystal (Bauru), mas distintas das demais águas oriundas da porção livre do sistema (Himalaia, Ubá e Villa Fonte). A composição da água Ananda indicou troca catiônica como fonte de sódio $\left(\mathrm{SiO}_{2} / \mathrm{Na}^{+}+\mathrm{K}^{+}-\mathrm{Cl}^{-}\right)$e precipitação de calcita $\left(\mathrm{Ca}^{2+} / \mathrm{Ca}^{2+}+\mathrm{SO}_{4}{ }^{2-}\right)$, processos característicos da zona confinada e de um grupo de amostras do SAB (ver subitem 4.6).

\subsection{Sistema Aquífero Serra Geral (SASG)}


À semelhança de Bertolo et al. (2007), foi possível agrupar as amostras do SASG em típico e profundo. Segundo Bertolo et al. (2007), o primeiro é constituído por águas bicarbonatadas cálcicas a sódicas e magnesianas, com pH neutro e valores TDS ou de cálcio mais variáveis, resultado de circulação rasa ou profunda. As relações iônicas $\left(\mathrm{Na}^{+}+\mathrm{K}^{+}-\mathrm{Cl}^{-} / \mathrm{Na}^{+}+\mathrm{K}^{+}-\mathrm{Cl}^{-}+\mathrm{Ca}^{2+}\right)$ apontaram fortemente o intemperismo de plagioclásio (diabásio). O segundo grupo, representado pela água Ibirá, corresponde à circulação profunda, e é do tipo bicarbonatadas sódicas, com quase ausência de cálcio e o magnésio, mas TDS é alto e $\mathrm{pH}>9$. As relações iônicas indicam como fonte de sódio a troca catiônica $\left(\mathrm{SiO}_{2} / \mathrm{Na}^{+}+\mathrm{K}^{+}-\mathrm{Cl}^{-} ; \mathrm{Na}^{+}+\mathrm{K}^{+}-\mathrm{Cl}^{-} / \mathrm{Na}^{+}+\mathrm{K}^{+}-\mathrm{Cl}^{-}+\mathrm{Ca}^{2+}\right)$.

Das amostras deste estudo (Figura 2D), Pureza Vital (ASB) é do grupo típico, enquanto as águas Ibirá e a Minajen Poço 213 m são profundas. Ambas, apresentaram valores consideráveis de $\mathrm{V}$, elemento-traço comum em rochas básicas, e as relações iônicas, além de apontarem a troca catiônica como fonte de sódio, indicaram também precipitação de calcita $\left(\mathrm{SiO}_{2} / \mathrm{Na}^{+}+\mathrm{K}^{+}-\mathrm{Cl}^{-}\right.$; $\left.\mathrm{Ca}^{2+} / \mathrm{Ca}^{2+}+\mathrm{SO}_{4}^{2-}\right)$ no caso das profundas.

O cálcio e o magnésio das rochas básicas da unidade estão quase ausentes na composição das águas profundas. Misturas com fluxos ascendentes de aquíferos subjacentes, como o SAG e reservatórios sedimentares paleozoicos, que percolam por fraturas explicariam a composição observada (Bittencourt et al., 2003; Rosa Filho et al., 2006; Bertolo et al., 2007). Em profundidade, a solubilidade da calcita diminui e, ao mesmo tempo, a troca iônica de cálcio por sódio também se torna comum. O Ba e o $\mathrm{Sr}$ são típicos elementos-traço que substituem o $\mathrm{Ca}$ na estrutura dos minerais, o que explica a menor concentração dos mesmos nas águas do grupo profundo.

\subsection{Sistema Aquífero Bauru (SAB)}

As duas amostras (Minajen e Soft) do SAB são do tipo bicarbonatadas mistas, com pH ligeiramente ácido e baixo valor de TDS (Figura 2D). Bertolo et al. (2007) classificaram amostras semelhantes como bicarbonatadas cálcicas a cálcicas-sódicas e observaram TDS um pouco maior ( $90 \mathrm{mg} / \mathrm{L}$ ). Ao mesmo tempo, observa-se valores proporcionais de cloreto, sódio e nitrato, que, podem indicar influência antrópica. É possível que a geologia local contribua com os íons cálcio e magnésio, como encontrado por Campos (1987), mas que a classificação mista reflita a contribuição antrópica.

Pelas relações iônicas, a fonte de sódio e cálcio é a dissolução de plagioclásios $\left(\mathrm{Na}^{+}+\mathrm{K}^{+}-\mathrm{Cl}^{-}\right.$ $\left./ \mathrm{Na}^{+}+\mathrm{K}^{+}-\mathrm{Cl}^{-}+\mathrm{Ca}^{2+}\right)$. Este resultado provavelmente deve-se à unidade superior do $\mathrm{SAB}$, formada por rochas sedimentares mais imaturas e com maiores quantidades de feldspato (Campos, 1987). A presença de cimento carbonático, principalmente na unidade Bauru Superior, pode contribuir como 
fonte de cálcio. No entanto, a indicação de intemperismo de minerais ferromagnesianos $\left(\mathrm{SiO}_{2} / \mathrm{Na}^{+}+\mathrm{K}^{+}-\mathrm{Cl}^{-}\right)$, não encontrada por Bertolo et al. (2007), sugere alteração da hidroquímica das águas pela adição antrópica de sódio e cloreto. Este sistema aquífero é livre por toda sua extensão, logo é mais vulnerável a contaminação.

Outras duas amostras (Levity e Santa Inês) podem resultar da mistura entre duas unidades aquíferas. Elas apresentaram maiores teores de sólidos dissolvidos e sódio que as do SAB, sendo classificadas como bicarbonatadas sódicas, mas, ao mesmo tempo, apresentaram $\mathrm{pH}$ e concentrações de sódio menores e cálcio e magnésio mais elevados que os esperados para o SASG. Estas características, segundo Bertolo et al. (2007), se referem a um grupo adicional de águas do $\mathrm{SAB}$, mais alcalino e de circulação profunda. Porém, as amostras Levity e Santa Inês ainda são apontadas como uma mistura em função das concentrações de $\mathrm{V}$ obtidas, que são maiores que a média das amostras do SAB e concordam com as amostras Ibirá e Minajen Poço $213 \mathrm{~m}$. A fonte de sódio foi atribuída à troca catiônica $\left(\mathrm{Na}^{+} / \mathrm{Na}^{+}+\mathrm{Cl}^{-}\right)$, mas as concentrações de cálcio e magnésio foram suficientemente altas para considerar o índice da calcita como insaturada, ou seja, não precipita nessas condições.

Acima foi sugerido que as águas Crystal (Bauru) e Ananda poderiam ser inseridas no grupo alcalino do SAB. A razão para a classificação da Crystal (Bauru) no grupo do SAG confinado são os dados geológicos obtidos pelo DNPM (2015), que mencionam essas águas como extraídas da Formação Botucatu/Grupo São Bento, uma das formadoras do SAG. Os níveis de TDS da amostras Ananda (260 mg/L) são característicos das águas do SAG confinado, diferente $(120 \mathrm{mg} / \mathrm{L})$ do mencionado por Bertolo et al. (2007). Apesar disso, as relações iônicas apontam troca catiônica e precipitação de calcita $\left(\mathrm{SiO}_{2} / \mathrm{Na}^{+}+\mathrm{K}^{+}-\mathrm{Cl}^{-} ; \mathrm{Ca}^{2+} / \mathrm{Ca}^{2+}+\mathrm{SO}_{4}{ }^{2-}\right)$, características comuns a setores dos três sistemas, SAG, SASG e SAB.

\section{CONCLUSÃO}

A composição das águas subterrâneas do estado de São Paulo, amostrada a partir da análise de águas minerais comerciais representativas dos sistemas aquíferos mais produtivos, espelham a heterogeneidade geológica do estado. De acordo com suas características, onze grupos de águas principais puderam ser identificados: SAC granitos, SAC gnaisses, SAT raso, SAT profundo, Passa Dois, SAG livre, SAG confinado, SASG típico, SASG profundo, SAB e SASP. Em geral são águas pouco salinas, e os maiores valores de sais dissolvidos encontram-se no SAT, SAG confinado e SASG profundo. As águas são predominantemente bicarbonatadas mas diferem entre unidades quanto à predominância dos cátions. Nas águas mais profundas é típica a troca iônica de cálcio por 
sódio e a precipitação de calcita. A composição de algumas águas minerais difere da esperada para o respectivo grupo, o que aponta influências de origem antrópica.

A Sistema Aquifero Tubarão (SAT)

EXPLANATION

- Profundas
- Rasas

: Rasas
: Jorabel
Aquiclude Passa Dois
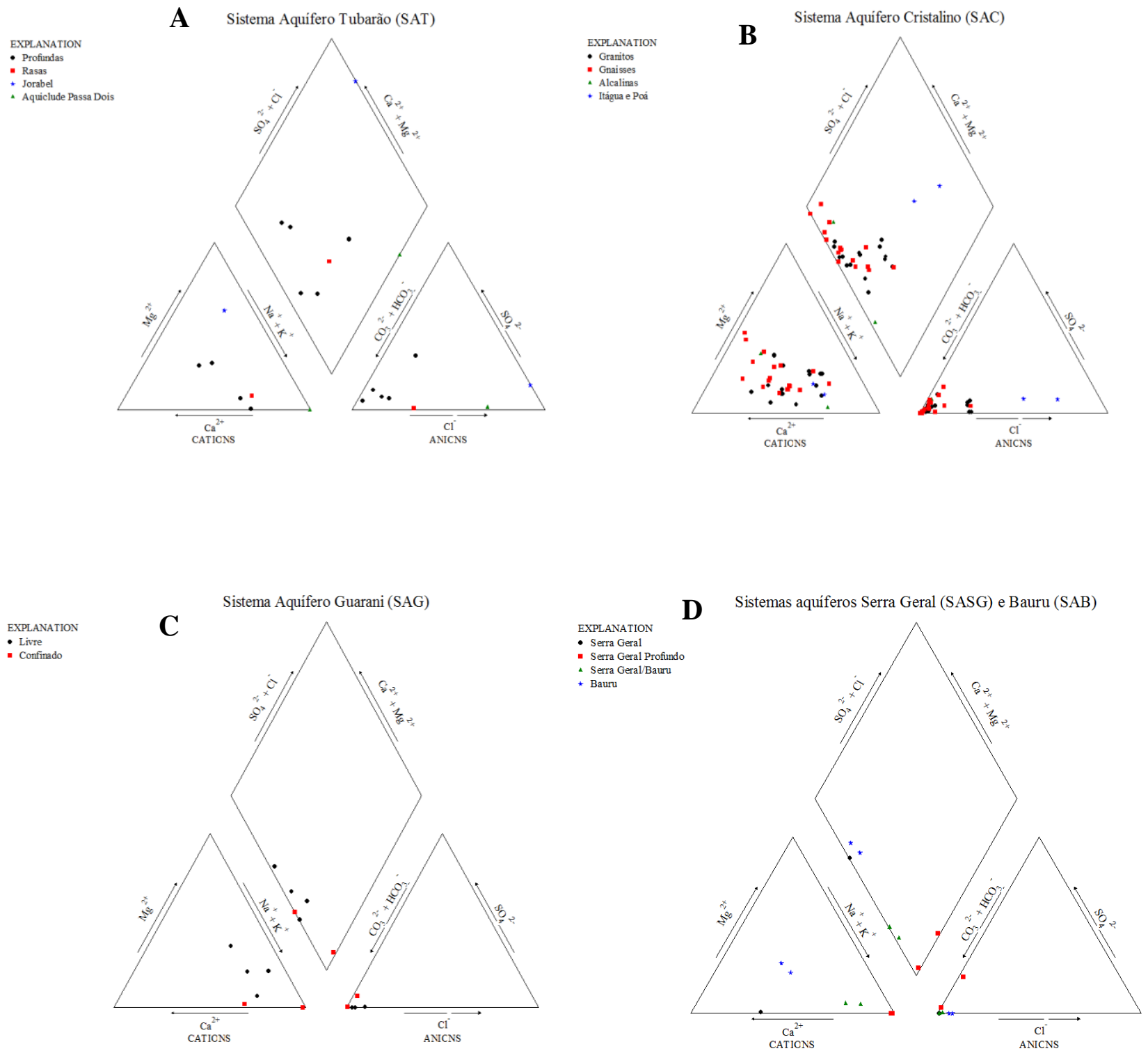

Figura 2. Diagramas de Piper para os diferentes sistemas aquíferos.

\section{AGRADECIMENTOS}

À CPRM pela disponibilização da lista contendo todas as marcas de águas minerais analisadas desde 2012, à CAPES pelos auxílios concedidos, à Sibele Ezaki e Mara Iritani do instituto geológico pelo fornecimento do mapa vetorizado das águas subterrâneas do estado de São Paulo e à todos os profissionais que gentilmente doaram amostras para este estudo. 


\section{REFERÊNCIAS BIBLIOGRÁFICAS}

BERTOLO, R. A.; HIRATA, R. C. A.; FERNANDES, A. J. 2007. Hidrogeoquímica das águas minerais envasadas do Brasil. Revista Brasileira de Geociências, v. 37, n. 3, p. 515-529.

CPRM - Serviço Geológico do Brasil. 2013. Água Mineral. Disponível em: <http://www.cprm.gov.br/publique/cgi/cgilua.exe/sys/start.htm?sid=46>. Acessado em: 2/abr/2016.

BITTENCOURT, A. V. L.; ROSA-FILHO, E. F. da; HINDI, E. C.; FILHO, A. C. B. 2003. A influência dos basaltos e de misturas com águas de aquíferos sotopostos nas águas subterrâneas do sistema aquífero Serra Geral na bacia do rio Piquiri, Paraná - BR. Revista Águas Subterrâneas, v. 17, p. 67-75.

BOCARDI, L. B. ROSTIROLlA, S. P.; DEGUCHI, M. G. F.; MANCINI, F. 2008. História de soterramento e diagênese em arenitos do grupo Itararé - implicações na qualidade de reservatórios. Revista Brasileira de Geociências, v. 38, n. 1 - Suplemento, p. 207-216.

CAMPOS, H. C. N. S. Contribuição ao estudo hidrogeoquímico do grupo Bauru no estado de São Paulo. São Paulo. 1987. 176 p. Tese de Mestrado. Instituto de Geociências, Universidade de São Paulo.

CAMPOS, H. C. N. S. 2013. Metodologia para estudos da qualidade das águas subterrâneas e sua aplicação para caracterização hidrogeoquímica do Aquífero Guarani. TERRAE DIDATICA, v. 9, n.2, p.114-131.

CHAPELLE, F. H. Geochemistry of Groundwater. In: HOLLAND, H. D.; TUKERKIAN, K. K. Treatise on Geochemistry. Columbia, South Carolina, USA: USGS, p. 425-449, 2003.

DAEE - Departamento de Águas e Energia Elétrica; IG - Instituto Geológico; IPT - Instituto de Pesquisas Tecnológicas do Estado de São Paulo; CPRM - Serviço Geológico do Brasil. Mapa de águas subterrâneas do Estado de São Paulo. Escala 1:1.000.000. Nota explicativa. Coordenação geral: Gerôncio Rocha - São Paulo, 2005.

DNPM - Departamento Nacional de Produção Mineral. 2015. Estudo diagnóstico das águas minerais e potáveis de mesa do Brasil. Disponível em: < http://www.dnpm.gov.br/dnpm/documentos/estudo-diagnostico/estudo-diagnostico-das-aguasminerias-e-potaveis-de-mesa-do-brasil.pdf/view> Acessado em: 1/jun/2016.

FEITOSA, F. A. C.; MANOEL FILHO, J. Hidrogeologia: conceitos e aplicações. 2. ed., Fortaleza: CPRM: REFO, LABHID-UFPE, 2000.

HEM, J. D. Study and Interpretation of Chemical Characteristics of Natural Waters. 3. ed., Publication of USGS, 1985.

HOUNSLOW, A. W. Water Quality Data: Analysis and Interpretation. New York: Lewis Publishers, 1995.

IRITANI, M. A.; YOSHINAGA-PEREIRA, S.; EZAKI, S.; ODA, G. H.; FERREIRA, L. M. R. 2011. Caracterização hidroquímica das águas subterrâneas no município de Itu (SP). Revista do Instituto Geológico, São Paulo, v. 32, n. 1/2, p. 11-26. 
IRITANI, M. A.; EZAKI, S. As águas subterrâneas do estado de São Paulo. 3. ed., São Paulo: Secretaria do meio ambiente, Instituto Geológico, 2012.

MONTANHEIRO, F.; CHANG, H. K.; GASTMANS, D. 2014. Estudo hidroquímico do sistema aquífero Tubarão (SAT) no município de Americana, SP. Revista do Instituto Geológico, São Paulo, v. 35, n. 1, p. 31-45.

OLIVA, A.; KIANG, C. H. Caracterização hidroquímica de águas subterrâneas no município de Rio Claro-SP. XII Congresso Brasileiro de Águas Subterrâneas. 2002.

PARISOT, E. H.; REBOUÇAS, A. C. 1983. Geoquímica de aquíferos do município de São Paulo. Boletim IG, Instituto de Geociências, USP, v. 14, p. 55-64.

REIMANN, C.; BIRKE, M. Geochemistry of European Bottled Water. Stuttgart: Borntraeger Science Publishers, 2010.

ROSA-FILHO, E. F. da; HINDI, E. C.; MANTOVANI, L. E.; BITTENCOURT, A. V. L. 2006. A importância do sistema aquífero Serra Geral para a cultura da soja no estado do Paraná. Águas Subterrâneas, v. 20, n. 2, p.49-56.

SZIKSZAK, M.; TEISSEDRE, J-M. 1977. Fontes da estância de Águas da Prata, estado de São Paulo. Boletim IG, Instituto de Geociências, USP, v. 8, p. 83-96.

SZIKSZAK, M.; TEISSEDRE, J-M. 1979. Fontes de Campos do Jordão. Boletim IG, Instituto de Geociências, USP, v. 10, p. 1-10.

VIDAL, A. C. Estudo hidrogeológico do aquífero Tubarão na área de afloramento da porção central do estado de São Paulo. Rio Claro. 2002. 122 p. Tese de Doutorado. Instituto de Geociências e Ciências Exatas, Universidade Estadual Paulista.

WU, F-T; CAETANO-CHANG, M. R. 1992. Estudo mineralógico dos arenitos das formações Piramboia e Botucatu no centro-leste do estado de São Paulo. Revista do Instituto de Geociências, São Paulo, v. 13, n. 1, p. 58-68. 